\title{
STRATEGI ENTREPRENEURIAL MARKETING GOCAMPUS.CO.ID DALAM MEMASARKAN PERGURUAN TINGGI SWASTA
}

\author{
Permadi \\ Program Studi Magister Manajemen Universitas Tarumanegara \\ madi_km@hotmail.com
}

\begin{abstract}
This study aims to market private universities in Indonesia and help students in facilitating the search for university information even become the number one educational information resource in Indonesia, where the analysis used is Matrix Strategic Position and Action Evaluation (SPACE). The research method used is descriptive qualitative. The study was conducted by observation on the environmental conditions of the gocampus.com industry in general and specifically based on existing facts. Analysis method used in this research is entrepreneurial marketing analysis which include strategy: Guerilla marketing, ambush marketing, and word of mouth marketing strategy The result from SPACE matrix quadrant indicates that GoCampus position is in aggressive quadrant with score on horizontal axis of 3 and score on the vertical axis of 2.2. Strategies that GoCampus can run for expansion (growth) from the perspective of entrepreneurial marketing strategy can be applied with several types: Guerrilla marketing, word of mouth marketing, and Ambush marketing. Gocampus can implement an expansion strategy and improve on the strength of human resources (for example by increasing the expertise of human resources, making efficiency in human resources), and increasing Gocampus technology accessibility (eg accessible on smartphones, plug and play available on google play, and sponsorship of google play applications that have a large market share), so that the company's performance can improve, and Gocampus expands its business to increase market share (eg penetrate the international university market).
\end{abstract}

Keywords: Internet, Education Portal, Web Portal, SPACE Matrix, Entrepreneurial Marketing, Word Of Mouth Marketing, Guerilla marketing, Ambush Marketing

\section{LATAR BELAKANG}

Pendidikan memiliki peranan penting dalam kehidupan manusia agar dapat secara aktif mengembangkan potensi diri. Pendidikan juga dapat mempengaruhi perkembangan manusia pada semua aspek kepribadian dan memahami beragam potensi yang dimiliki secara maksimal yaitu dilakukan dengan cara pengembangan potensi individu yang setinggitingginya dalam ruang lingkup fisik, intelektual, emosional, dan spiritual sesuai dengan perkembangan serta karakteristik lingkungan fisik dan lingkungan social budayanya. Peningkatan kualitas sumber daya manusia tidak dapat lepas dari kualitas pendidikan, semakin tinggi kualitas pendidikan maka akan semakin tinggi kualitas sumber daya manusia yang akan didapat. Indonesia perlu meningkatkan mutu sumber daya manusianya untuk meningkatkan ilmu pengetahuan dan teknologi agar negara kita dapat semakin maju. Mentri keuangan saat ini Ibu Sri Mulyani Indrawati sudah melakukan pengelolaan dana pendidikan (LPDP) dengan memberikan beasiswa bagi siswa siswi berprestasi untuk dapat meneruskan pendidikanya di dalam maupun diluar negri. Program tersebut bertujuan untuk meningkatkan sumber daya manusia agar kelak mereka dapat menerapkan ilmu yang sudah dipelajari di Indonesia (Primadhyta 2017).

Selain pengembangan pendidikan, perkembangan ilmu pengetahuan dan teknologi informasi semakin pesat berkembang, bahkan penggunaanya sudah masuk pada berbagai lapisan masyarakat, dapat dilihat dari setiap instansi, sekolah, maupun lembaga pendidikan sudah menggunakan alat komputer dan Internet sebagai sarana penunjang. Teknologi 
informasi merupakan sebuah teknologi yang digunakan untuk pengelolaan data sehingga mampu menghasilkan informasi yang berkualitas dan bernilai guna tinggi bagi penggunanya. Data mendikbud menunjukkan total siswa SMA pada tahun ajaran 2015-2016 sebesar 8.647.394 siswa yang tersebar di seluruh Indonesia (Badan Pusat Statistik, 2017). Penyebaran informasi mengenai beasiswa dan perguruan tinggi masih terbatas di beberapa daerah di Indonesia. Metode penyebaran informasi yang sekarang digunakan yaitu melalui Internet. Internet merupakan satu jaringan komunikasi tanpa batas yang mencakup jutaan komputer pribadi yang tersebar di seluruh dunia dengan menggunakan dukungan dari media komunikasi seperti satelit.

Data APJII, 2016 menunjukkan sebesar 25,3\% penggunaan Internet untuk mencari informasi terbaru. Pada saat ini akses Internet sudah mulai digencarkan di seluruh wilayah di Indonesia. Penggunaan Internet di Indonesia mengalami peningkatan dari 2014 sebesar 88,1 juta menjadi 132,7 juta pada tahun 2016 (APJII, 2016). Peningkatan tersebut menunjukkan bahwa penetrasi Internet telah berkembang cukup cepat di Indonesia, meskipun masih terdapat daerah yang perkebanganya masih membutuhkan dukungan pemerintah untuk membangun infrastruktur agar Internet dapat dengan mudah diakses dan pengajaran akan pentingnya penggunaan Internet. Perkembangan Internet yang cepat tersebut juga merubah gaya hidup sebagian besar masyarakat Indonesia, hal tersebut terlihat dari tumbuhnya beberapa toko online (e-commerce) dan sarana transportasi online. Tumbuhnya industri di dunia maya membuat masyarakat semakin mudah dalam menjual dan mencari informasi yang mereka butuhkan.

Dengan adanya latar belakang ini maka penulis mengambil judul "STRATEGI ENTREPRENEURIAL MARKETING GOCAMPUS.CO.ID DALAM MEMASARKAN PERGURUAN TINGGI SWASTA".

\section{TUJUAN PENELITIAN}

Sesuai dengan rumusan masalah diatas, penelitian ini mempunyai tujuan untuk memasarkan perguruan tinggi swasta di Indonesia dan membantu siswa siswi dalam mempermudah mencari informasi perguruan tinggi bahkan menjadi sarana sumber informasi pendidikan nomor satu di Indonesia.

\section{TINJAUAN PUSTAKA \\ Web Portal}

Web portal atau biasa disingkat portal, adalah jenis gateway website yang berfungsi sebagai "anchor site" yang menawarkan jasa atau layanan seperti online shopping malls, email support, komunitas forum, berita saat ini dan cuaca, harga saham, informasi wisata, dan link ke subjek popular yang lain. Web Portal yang memiliki fasilitas lengkap mampu menciptakan ketergantungan bagi para pengunjung agar dapat sering datang ke website tersebut dan akhirnya mereka menjadi member dan menjadikan Web Portal tersebut halaman pertama yang dibuka setiap kali membuka Internet browsernya (Mishra and Bartram, 2002).

Web portal terdiri dari 2 jenis yaitu portal horizontal dan portal vertikal. Portal Edukasi tersebut dibuat oleh suatu instantsi tertentu yang bisnis utamanya berada di bidang pendidikan. Portal jenis ini umumnya berisikan tentang latar belakang instansi tersebut, filosofinya, penyedia dana, dan anggota staf. Informasi tentang apa yang telah dilakukan atau yang akan dilakukan oleh instansi tersebut juga dicantumkan didalamnya seperti hasil penelitian yang pernah dibuat dan prestasi yang pernah dicapai. Portal tersebut pada umumnya dibuat oleh sekolah atau lembaga pendidikan perguruan tinggi. Instansi pendidikan sangat memerlukan portal tersebut agar dapat memberikan penjelasan secara tertulis dan visual semenarik mungkin kepada pengunjungnya agar mereka dapat tertarik dengan instansi tersebut. Instansi pendidikan juga menggunakan portal tersebut untuk dapat menjangkau 
calon siswa siswi nya yang berada di wilayah yang jauh agar mereka dapat merasakan keadaan lingkungan secara tidak langsung (Mishra and Bartram, 2002).

\section{Pemasaran}

Menurut Kotler dan Amstrong (2008), Pemasaran adalah proses manajemen yang bertanggung jawab untuk mengidentifikasi, mengantisipasi dan memuaskan kebutuhan pelanggan secara menguntungkan. . Pemasaran merupakan fungsi yang memiliki kontak paling besar dengan lingkungan eksternal, padahal perusahaan hanya memiliki kendali yang terbatas terhadap lingkungan eksternal. Oleh karena itu, pemasaran memainkan peranan penting dalam pengembangan strategi. Definisi strategi pemasaran yang lain adalah pernyataan pokok mengenai dampak yang diharapkan akan dicapai dalam hal permintaan pada target pasar yang ditentukan.

\section{Perilaku Konsumen}

Perilaku konsumen merupakan sikap seorang individu dalam mengambil keputusan untuk melakukan konsumsi dari suatu barang maupun jasa (Schiffman \& Kanuk, 2008). Perilaku konsumen berhubungan dengan aktifitas mental dan fisik hingga akhirnya menghasilkan keputusan untuk membeli, membayar, dan menggunakan suatu produk atau jasa tertentu.

\section{Analisa Lingkungan Bisnis}

Analisa lingkungan bisnis merupakan proses perencanaan strategi untuk mengamati lingkungan bisnis dalam melihat adanya ancaman atau peluang. (Weatherson dan Brooks, 2000). Analisis tersebut memerlukan dua tahapan yang harus dianalisa yaitu analisis lingkungan internal dan analisis lingkungan eksternal. Analisis lingkungan internal adalah analisis yang dilakukan didalam perusahaan itu sendiri yang terdiri dari struktur organisasi, manajemen, budaya, dan sumber daya. Lingkungan internal dapat dikontrol oleh pengusaha yang memberikan pengaruh dari rencana bisnis dan implementasi strategi pemasaran Analisis lingkungan eksternal merupakan suatu evaluasi yang berada diluar kendali perusahaan. Analisis tersebut bertujuan untuk mengembangkan peluang-peluang terbatas yang dapat dimanfaatkan perusahaan serta ancaman yang dapat dihindari (David, 2011).

\section{Analisis Lingkungan Industri (Porter's Five Forces)}

Lingkungan Industri terdiri dari beberapa faktor yang saling mempengaruhi dalam satu perusahaan untuk menentukan strategi yang akan dijalankan yaitu berasal dari pendatang baru, pemasok, pembeli, barang pengganti, dan intensitas persaingan. Jika suatu perusahaan semakin dapat mempengaruhi lingkungan industri makan akan semakin besar kemungkinan satu perusahaan untuk mendapatkan keuntungan yang lebih besar. Lingkungan Industri dibutuhkan untuk dapat menciptakan keunggulan kompetitif. (Porter, 2008).

\section{Strategic Position and Action Evalution (SPACE) Matrix}

Matrik SPACE terdiri dari kerangka kerja empat kuadran yang terdiri dari strategi agresif, konservatif, defensif, dan komprehensif, dimana keempat kuadran ini mengindikasikan strategi mana yang paling cocok dengan organisasi tertentu. Sumbu matrik SPACE menggambarkan dua dimensi internal dan dua dimensi eksternal. Dua dimensi internal meliputi kekuatan (financial strength $=$ FS) dan keunggulan kompetitif (competitive advantage $=\mathrm{CA}$ ). Sedangkan dua dimensi eksternal meliputi stabilitas lingkungan (environmentat stability = ES) dan kekuatan industri (industrial strength = IS) (David, 2005). Proses analisis matriks SPACE dimulai dari penilaian kekuatankekuatan finansial dan keunggulan kompetitif yang dimiliki perusahaan, sekaligus penilaian tentang stabilitas lingkungan dan kekuatan industri. Analisis matriks SPACE akan 


sangat berguna untuk merumuskan dan melaksanakan sasaran dan tujuan
perusahaan. Berdasarkan informasi yang diperoleh dari analisis matriks SPACE, dipandang perlu untuk mengadakan perubahan-perubahan baik dalam sasaran, tujuan, kebijaksanaan, dan strategi perusahaan yang sudah ada.

\section{Entrepreneurial Marketing}

Pada era ekonomi yang penuh dengan perkembangan teknologi, perlu dilakukan pendekatan yang berbeda untuk dapat mempertahankan hubungan dengan konsumen yaitu dengan entrepreneurial marketing (Bjerke dan Hultman, 2002). Terdapat empat macam pendekatan berdasarkan konsep, strategi, metode, dan sumber pencarian informasi yaitu: Innovation Oriented, "Bottom up" Strategies, Interaktif dan Word Of Mouth Marketing dan Networking.

\section{Implementasi Strategi Entrepreneurial Marketing}

Strategi entrepreneurial marketing dapat diaplikasikan dengan beberapa tipe yaitu: Guerrilla marketing, Ambush marketing, dan word of mouth marketing. Tujuan dilakukan strategi Ambush marketing adalah agar dapat menciptakan kesan menjadi sponsor resmi tanpa mengeluarkan uang untuk menjadi sponsor, mengimbangi persaingan, dan untuk dapat menggunakan uang yang ada dengan tidak menjadi sponsor melainkan pada iklan. Strategi word of mouth marketing adalah suatu produk atau layanan tertentu dipromosikan oleh satu orang ke orang lain tanpa sepengetahuan, perintah, bantuan atau pengawasan perusahaan (Hisrich dan Ramadani, 2017).

\section{METODOLOGI PENELITIAN}

Metode penelitian yang digunakan adalah deskriptif kualitatif karena penelitian menunjukkan keadaan sebenarnya pada website gocampus.co.id dengan memakai prosedur ilmiah sesuai fakta yang ada. Penelitian dilakukan dengan observasi terhadap kondisi lingkungan industri gocampus.co.id secara umum dan khusus berdasarkan fakta yang ada. Metode Analisis yang dipakai pada penelitian ini yaitu analisis SPACE Matrix untuk mengetahui kekuatan internal dan eksternal perusahaan yang bertujuan untuk menentukan arahan strategi perusahaan kemudian mengaplikasikan strategi entrepreneurial marketing.

\section{HASIL \& KESIMPULAN}

\section{Analisis Strategic Position Action Evaluation (SPACE) Matriks}

Proses analisis matriks SPACE dimulai dari penilaian kekuatan-kekuatan finansial dan keunggulan kompetitif yang dimiliki perusahaan sekaligus penilaian tentang stabilitas lingkungan dan kekuatan indutri. Kekuatan finansial (FS) dinilai dari variabel kinerja keuangan yaitu Return on Investment (ROI) dan modal kerja. Keunggulan kompetitif (CA) diukur dengan Pangsa Pasar, Tingkat Pertumbuhan Penjualan, Tingkat Pertumbuhan Pasar dan Loyalitas konsumen. Kekuatan industri (IS) diukur dengan potensi pertumbuhan, kemudahan pendatang baru memasuki pasar, teknologi know-how, dan utilisasi sumber daya. Stabilitas lingkungan (ES) perusahaan diukur dengan perubahan teknologi, hambatan masuk pasar dan pengembangan potensial dari produk subtitusi

Berdasarkan matriks SPACE didapat hasil total skor masing-masing dimensi yang terdiri dari kekuatan finansial mempunyai rata-rata skor sebesar 4.5, kekuatan industri ratarata skor sebesar 4.5, keunggulan kompetitif sebesar -1,5, dan stabilitas lingkungan sebesar -2.3, dengan menjumlahkan rata-rata skor pada arah horizontal yaitu Keunggulan Kompetitif (CA) dan Kekuatan Industri (IS) serta arah vertikal yaitu Kekuatan Finansial (FS) dan Stabilitas Lingkungan (ES) maka diperoleh skor sumbu X sebesar 3 dan skor sumbu Y sebesar 2.2. Gambar SPACE Matriks sebaai berikut: 
FS

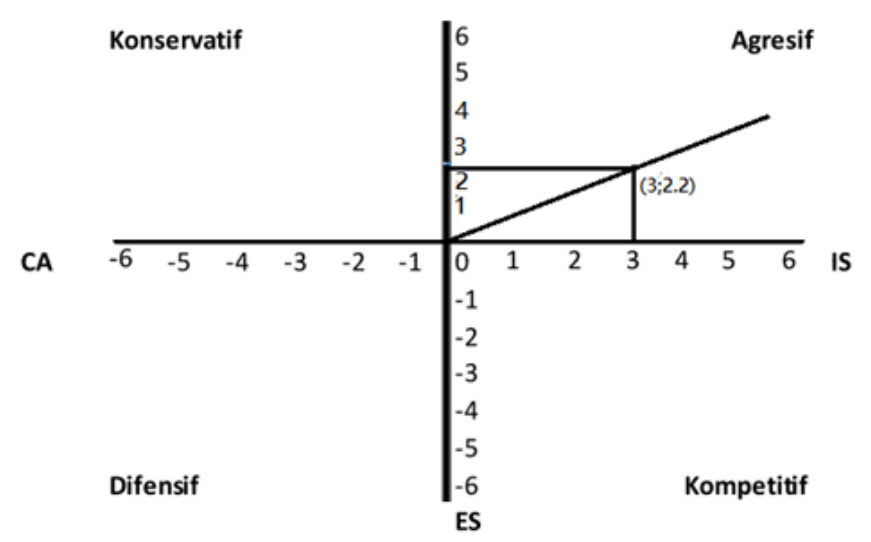

Hasil dari kuadran SPACE matriks menunjuk bahwa posisi GoCampus berada pada kuadran agresif dengan skor pada sumbu horizontal sebesar 3 dan skor pada sumbu vertikal sebesar 2.2. Pada posisi ini suatu perusahaan atau organisasi tersebut berada pada posisi yang terbaik untuk menggunakan kekuatan internal. Perusahaan dalam posisi ini memiliki keunggulan bersaing.

Berdasarkan hasil Matriks SPACE, maka posisi GoCampus berada pada posisi kuadran kanan atas yaitu strategi agresif, dimana perusahaan berada pada posisi terbaik untuk menggunakan kekuatan internalnya, yang berguna untuk memanfaatkan peluang ekstrenal, mengatasi kelemahan internal dan menghindari ancaman eksternal. Dengan demikian, penetrasi pasar, pengembangan pasar, pengembangan produk, integrasi ke belakang, integrasi ke depan, integrasi horizontal atau strategi kombinasi semuanya bisa digunakan, tergantung pada kondisi spesifik yang dihadapi perusahaan,

Strategi yang dapat dijalankan oleh GoCampus untuk ekspansi (growth) dari sudut pandang strategi entrepreneurial marketing dapat diaplikasikan dengan beberapa tipe yaitu: Guerrilla marketing, word of mouth marketing, dan Ambush marketing. Semua strategi tersebut saling berhubungan satu sama lain untuk dapat menciptakan dampak yang maksimal pada konsumen tetapi dengan pengeluaran yang seminimal mungkin. Gocampus dapat membuat program perlombaan penulisan blog secara online, atau penulisan kisah dan pengalaman dengan Gocampus di medsos. Dengan selalu menghubungkan Gocampus dengan komunias online maka word of mouth Gocampus pun juga dapat berkembang di internet. Gocampus dapat mensponsori suatu acara kegiatan seperti pertandingan olah raga antar sekolah, bazaar sekolah, lomba jalan sehat dan beberapa tema yang sesuai dengan misi Gocampus. Selain itu promosi dapat dilakukan dengan menayangkan iklan pada acara siaran pendidikan dan yang sejenis, menayangkan iklan pada suatu acara dengan tema pendidikan, seminar remaja maupun dengan melakukan promosi kesebuah acara secara mendadak. Penggunaan strategi ini dapat membantu perusahaan meningkatkan pangsa pasarnya.

\section{PENUTUP}

Kesimpulan Strategi yang tepat untuk Gocampus adalah strategi penetrasi pasar untuk ekspansi (growth). Strategi yang harus dilakukan oleh Gocampus Antara lain (1) Implementasi Strategi Guerrilla marketing yang selama ini dilakukan Gocampus adalah mengadakan event education fair kesekolah-sekolah untuk memperkenalkan Gocampus. Setiap bulan selalu diadakan event education fair kesekolah-sekolah yang diikuti oleh beberapa kampus yang menjadi pelanggan dari Gocampus. Penetrasi agesif Gocampus dapat dilakukan dengan menambah frekwensi education fair kesekolah-sekolah. Dengan kekuatan financial dan sumber daya yang dimilki Gocampus dapat mengembangkan berbagai jenis 
event education fair yang lebih menarik bagi siswa-siswa sekolah sehingga dapat memperluas penetrasi pasar dari Gocampus. GoCampus bekerjasama dengan beberapa kampus dalam pemberian diskon biaya pendidikan untuk siswa yang mendaftar melalui Gocampus. (2) Implementasi Strategi Word Of Mouth Marketing Untuk Meningkatkan pelanggan Pada Gocampus yaitu melalui 2 model: Organic Word Of Mouth Marketing dan Amplifield Word Of Mouth Marketing. Pelaksanaan Organic Word Of Mouth Marketing dengan cara Gocampus selalu berusaha memberikan pelayanan yang sebaikbaiknya kepada semua konsumen. Dibuktikan dengan adanya konsumen yang merasa puas dengan layanan Gocampus kemudian mengajak orang-orang terdekatnya untuk menggunakan layanan Gocampus. Adapun model yang kedua adalah Amplifield Word Of Mouth, Gocampus sengaja membuat kampanye yang berisi jenis layanan Gocampus, dan promo yang ditawarkan melalui media sosial seperti WhatsApp, Blackberry Messenger, Facebook, Line, twitter, Instagram, dan Website resmi Gocampus untuk mempercepat proses word of mouth. (3) Implementasi Strategi Word Of Mouth Marketing Untuk Meningkatkan pelanggan Pada Gocampus yaitu melalui 2 model: Organic Word Of Mouth Marketing dan Amplifield Word Of Mouth Marketing. Pelaksanaan Organic Word Of Mouth Marketing dengan cara Gocampus selalu berusaha memberikan pelayanan yang sebaikbaiknya kepada semua konsumen. Dibuktikan dengan adanya konsumen yang merasa puas dengan layanan Gocampus kemudian mengajak orang-orang terdekatnya untuk menggunakan layanan Gocampus. Adapun model yang kedua adalah Amplifield Word Of Mouth, Gocampus sengaja membuat kampanye yang berisi jenis layanan Gocampus, dan promo yang ditawarkan melalui media sosial seperti WhatsApp, Blackberry Messenger, Facebook, Line, twitter, Instagram, dan Website resmi Gocampus untuk mempercepat proses word of mouth. (4) Gocampus mempunyai potensi penjualan yang masih sangat tinggi. Agar Gocampus lebih meningkatkan penjualan dengan meningkatkan aspek pemasaran, melakukan strategi penetrasi dengan mengaplikasikan strategi entrepreneurial marketing. (5) Gocampus lebih menjalin kerjasama dengan kampus-kampus dan sekolah-sekolah yang menjadi pangsa pasar Gocampus. Misalnya dengan mengadakan event bersama dalam program education fair, menjalin sponsorship dalam kegiatan sekolah-sekolah. (6) Gocampus dapat lebih memfokuskan pada calon konsumen, dan sekolah-sekolah yang mempunyai standar sosial yang baik. Juga Gocampus dapat meluncurkan program-program yang lebih menarik minat konsumen.

Saran Terkait dengan hasil penelitian ini, saran yang dapat diberikan adalah: Gocampus hendaknya dapat memilih strategi yang sesuai. Misalnya Gocampus dapat menerapkan strategi ekspansi (growth) dan meningkatkan pada kekuatan SDM (misalnya dengan menambah keahlian tenaga SDM, membuat effisiensi pada tenaga SDM), serta meningkatkan aksebilitas teknologi Gocampus (misalnya dapat diakses di smartphone, plug and play tersedia pada google play, serta iklan dan sponsor pada aplikasi-aplikasi google play yang mempunyai pangsa pasar yang luas), sehigga kinerja perusahaan dapat meningkat, serta Gocampus melakukan ekspansi usaha untuk menambah pangsa pasar (misalnya merambah pasar universitas internasional).

\section{DAFTAR PUSTAKA}

APJII. (2017). “Asosiasi Penyelenggara Jasa Internet Indonesia”. Pengguna Internet Indonesia. 3 Mei 2017, Available from https://apjii.or.id/survei2017.

Badan Pusat Statistik Indonesia. (2018). "Data Mahasiswa Perguruan Tinggi". Available from https://www.bps.go.id/statictable/2015/09/14/1839/jumlah-perguruan-tinggimahasiswa-dan-tenaga-edukatif-negeri-dan-swasta-di-bawah-kementrian-pendidikandan-kebudayaan-menurut-provinsi-2013-2014-2014-2015.html. 
Bjerke, B dan Hultman, C.M. (2002). "The Growth of Small Firms in the New Economic Era". Cheltenham: Edward Edgar.

David, Fred. (2011). "Strategic Management: Concept and Cases (15 ${ }^{\text {th }}$ Edition)". South Carolina: Francis Marion University.

Hisrich, R D, Ramadani V. (2017). "Effective Entrepreneurial Management: Strategy, Planning, Risk Management, and Organization". Switzerland: Springer Nature.

Kotler, Philip. Amstrongg, Gary M. Wong, Veronica, \& Saunder, John A. (2008). "Principles of Marketing". Financial Times Prentice Hall.

Mishra, K A, John Bartram. (2002). "Commonwealth of Learning". Canada: Office of the United Nation High Commissioner for Refugees.

Porter, Michael E. (2008). "On Competition: Updated and Expanded Edition". Harvard Business School Press/Simon and Schuster.

Primadhyta, S. (2017). "Sri Mulyani Sebar Rp 22,5 Triliun untuk beasiswa LPDP 2017”. CNN Indonesia. Homepage online. 3 Juni 2017 Available from http://www.cnnindonesia.com/ekonomi/20170131131232-78-190261/sri-mulyanisebar-rp225-triliun-untuk-beasiswa-lpdp-2017/.

Schiffman dan Kanuk. (2008). "Perilaku Konsumen". Edisi 7. Jakarta: PT. Indeks Gramedia.

Weatherson, Jamie., and Brooks, Ian. (2000). "The Business Environment: Changes and Changes (Illustrated Edition)". New York: Financial Times.

Weinhardt, Christof, Philip, Becker, Freimut, Robert, W., et al. (2011). "Business Aspects of Web Services". New York: Springer Heidelberg Dordrecht. 
